\title{
Sueños de Carnaval otomí en la Sierra Norte de Puebla
}

\author{
Jorgelina Reinoso Niche
}

\section{Resumen}

En la Sierra Norte de Puebla se practica la medicina tradicional otomí en la cual los curanderos bädi aprenden todo lo que saben gracias a sus dioses llamados antiguas. Cuentan los otomíes que Zithu, el diablo, es la antigua que más poder tiene y es el gran maestro de todos los curanderos, pues posee mucha fuerza, mucho nzahki, por eso se le ofrecen grandes ofrendas durante el Carnaval otomí, pues es en esta fiesta que Zithu llega a jugar, divertirse y encontrarse con los humanos. En el Carnaval todos los curanderos colocan una ofrenda en su casa para Zithu y cada día se visita una casa y se baila alrededor de ella. Sin embargo, para poder poner una ofrenda primero tienen que soñarla, es decir, los curanderos son visitados en sueños por el diablo y éste les dice cómo deben ser.

Este artículo tiene como objetivo exponer el importante papel que tienen los curanderos dentro del Carnaval otomí que se realiza en la comunidad de Ixtololoya, municipio de Pantepec en la Sierra Norte de Puebla.

Palabras clave: otomí, carnaval, diablo, antiguas, bädi.

\section{Dreams of Otomi Carnival in the Northern Sierra of Puebla}

\begin{abstract}
In the Sierra Norte of Puebla, Otomi traditional medicine is practiced by bädi healers who learn everything they know through their ancient gods called antiguas. The Otomi people affirm that Zithu, the devil, is the most powerful antigua and the great master of all healers, because it has much strength, a lot of nzahki. This is why such deity is proffered great offerings during Otomi Carnival, as this is the feast in which Zithu comes to play, have fun and engage with humans. During Carnival, all healers place an offering for Zithu at their own homes and a different house is visited every day, to dance around the corresponding offering. However, healers first have to dream the offering. In other words, healers are visited by the devil in their dreams to tell them how the Carnival offerings must be.

This article aims to show the important role played by healers within the Otomi Carnival that takes place in the community of Ixtololoya, municipality of Pantepec in the Sierra Norte of Puebla.
\end{abstract}

Keywords: Otomi, Carnival, devil, antiguas, bädi.

DOI: http://doi.org/10.22201/codeic.16076079e.2019.v20n2.a4 


\section{Jorgelina Reinoso Niche}

Es licenciada en Etnología, maestra y doctora en Antropología Social por la Escuela Nacional de Antropología e Historia, ENAH. Actualmente realiza una estancia posdoctoral en la Benemérita Universidad Autónoma de Puebla.

Ha realizado largos períodos de trabajo de campo en comunidades otomíes de la Sierra Norte de Puebla, en el Estado de México y con otomíes migrantes en situación de calle de la Ciudad de México. Sus áreas de interés son las concepciones del cuerpo y la menstruación, sexualidad, medicina tradicional, chamanismo y cosmovisión otomí. Ha publicado varios artículos y realizado varias ponencias sobre el chamanismo y la cosmovisión otomí. Participa como investigadora en el proyecto "Procesos de adivinación/sanación/reparación/propiciación en el contexto del conocimiento y la práctica del chamanismo de los pueblos indígenas" del CONACYT.

\section{Introducción}

Para los otomíes el cosmos está poblado por los vivos y por sus antepasados muertos, dioses llamados antiguas, los cuales son seres sagrados, prehispánicos, que habitan en otro espacio. Según Dow, "El rasgo más importante de los seres que pueblan el mundo es que son entes sociales con quienes el hombre puede tener relaciones" (1974: 95). Así, estas características son fundamentales para entender a las antiguas.

Las antiguas siempre se presentan para pedir ofrenda, a la cual los otomíes llaman costumbre, un ritual en donde se les ofrece comida, bebida, ropa, canto y baile: la paga que realizan en agradecimiento a todo lo que les brindan. Al respecto, Galinier menciona:

[...] En otomí, "costumbre" se traduce por la palabra mate, en el sentido del ritual específicamente indígena, y no existe ningún término que designe la tradición o las creencias en general. Ahora bien, cuando un interlocutor otomí dice mate, hace referencia a una institución precisa [...] Además, mate está compuesto por dos morfemas, uno de los cuales es el locativo de ma "lugar" y el otro, te, significa "vida". El lugar de la vida es pues por excelencia el del ritual [...] se entiende siempre que en el mate hay una acción de gracias en reciprocidad por una intervención divina (1990: 39-40).

Dentro de las antiguas hay jerarquías y el que se encuentra más arriba es Zithu, luego siguen sus ayudantes, los cuales son otros diablos de menor poder como el Viejo costal o el Señor con cabeza de viejo, y luego las demás. Dentro de las antiguas que piden costumbre encontramos al diablo Zithu y sus ayudantes. Para aproximarnos a las antiguas, Galinier describe al Viejo costal como:

[...] una envoltura universal que contiene todas las experiencias de cualquier sujeto como si fueran acumuladas en "archivos". Al explorar este almacén, los actores presentes en el sueño capturan estas imágenes anónimas, "universales". Pueden 
ser decodificadas y descifradas gracias a una llave maestra: no expresan la experiencia de un sujeto en particular sino, al contrario, los acontecimientos públicos que han ocurrido en el "mundo de abajo". De acuerdo con esta lógica nativa obsesionada con la polarización de contrarios, esta gente muerta inicia un desgaste energético, es decir la vida: un movimiento de "ida y vuelta" [...], característico del proceso circulatorio de los difuntos (2009: 106-107).

Todo lo que existe en la cosmovisión otomí y todo lo que los otomíes saben para sobrevivir en este mundo es gracias a Zithu y a las antiguas. Por esta razón es necesario hacer varios costumbres durante el año y dejarle durante el Carnaval, que es la gran fiesta para Zithu, la ofrenda que él exija.

En este artículo se describe la importancia del bädi otomí dentro del Carnaval, ya que es él quien sueña las ofrendas que se le dejan a Zithu en su fiesta y en los costumbres que se realizan durante ésta.

\section{El Carnaval otomí}

El Carnaval otomí, como todos los carnavales del mundo, no tiene una fecha fija establecida, su realización coincide con el calendario judeo-cristiano. Generalmente se realiza a finales de febrero o principios de marzo y dura entre cuatro días a una semana.

Dentro de la antropología, el Carnaval otomí ha sido muy estudiado. En 1960, Roberto Williams García se consolidó como un parteaguas en el tema y desde entonces se siguen produciendo una gran cantidad de investigaciones como la de Siqueiros (1997), Robledo (2005) y, la más importante, la de Galinier (1990, 2001, 2009).

Imagen 1. Bädi curando durante el Carnaval otomí. Reinoso, 2014.

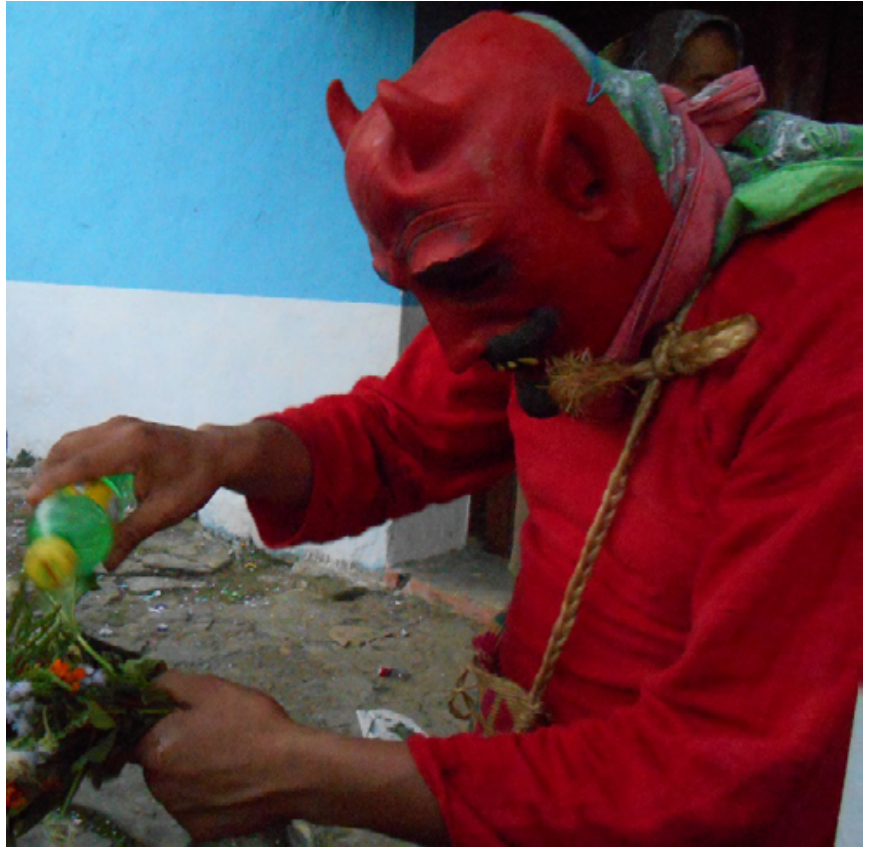


Imagen 2. Actores que juegan en el Carnaval otomí para renovar la energía del mundo. Reinoso, 2014
Galinier manifiesta que el Carnaval otomí es un juego en donde los ancestros se presentan en el mundo de los vivos para renovarse. Es un ritual en donde el mundo se vuelve un gran escenario: los actores se disfrazan de antepasados otomíes como el diablo, el Viejo costal, el Señor con cabeza de viejo, entre otros. Estos seres vienen desgastados, arrugados, viejos, cansados y llegan a este mundo de los vivos sin energía, ya podridos y agotados, con el objetivo de renovarse mediante la ingesta de alimentos y bebidas, el baile y la muerte súbita que genera el Carnaval; asimismo, se renueva la energía de la tierra gracias a la energía que se genera en el cosmos por el encuentro entre vivos y muertos.

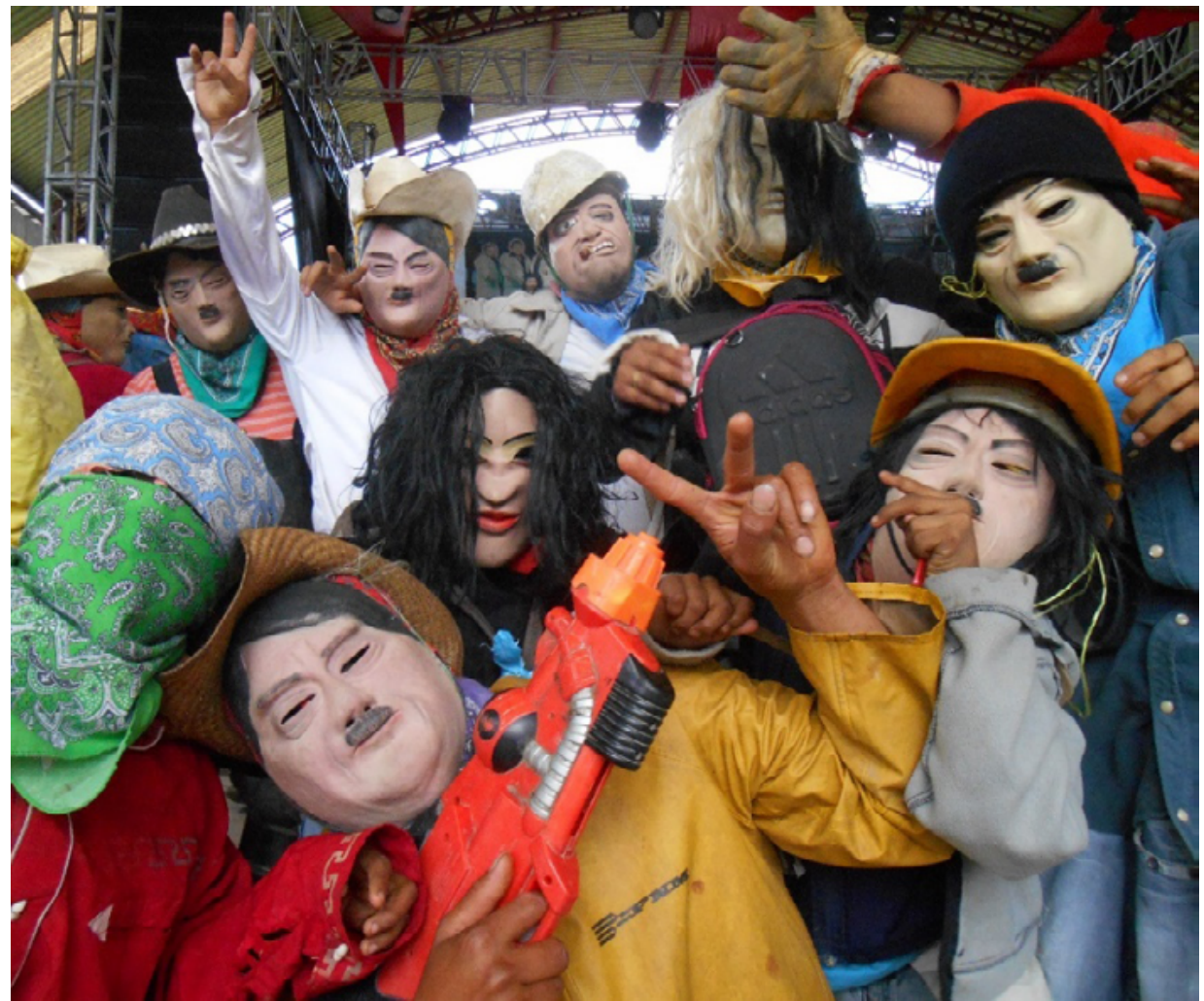

Todas estas deidades y antepasados que se presentan en el Carnaval otomí viven en el mundo de los muertos, la parte de abajo del cosmos, en donde se encuentra lo sucio, lo podrido y los fluidos corporales que contaminan el mundo:

La calidad del ambiente escatológico que constituye el mundo subterráneo revela la fuerza de un imperativo mayor: que el mundo sea ensuciado, más allá de toda media, y la vida renacerá. Está en juego una doctrina energética que descubre en la saturación el punto de reanudación, de impulso de una dinámica cósmica [...] el agotamiento permite comprender la degradación energética del universo (Galinier, 2009: 79).

Esta idea manifiesta un intercambio de energía entre vivos y muertos, para agotarse, "morirse" en la fiesta para volver a renacer, debe de haber podredumbre que genere la muerte para que haya vida. Esta vida es la que esperan los otomíes en la siembra de los vegetales, que empezará unos días después de que termine la fiesta. 
Imagen 3. Juegos sexuales durante el Carnaval. Reinoso, 2014.

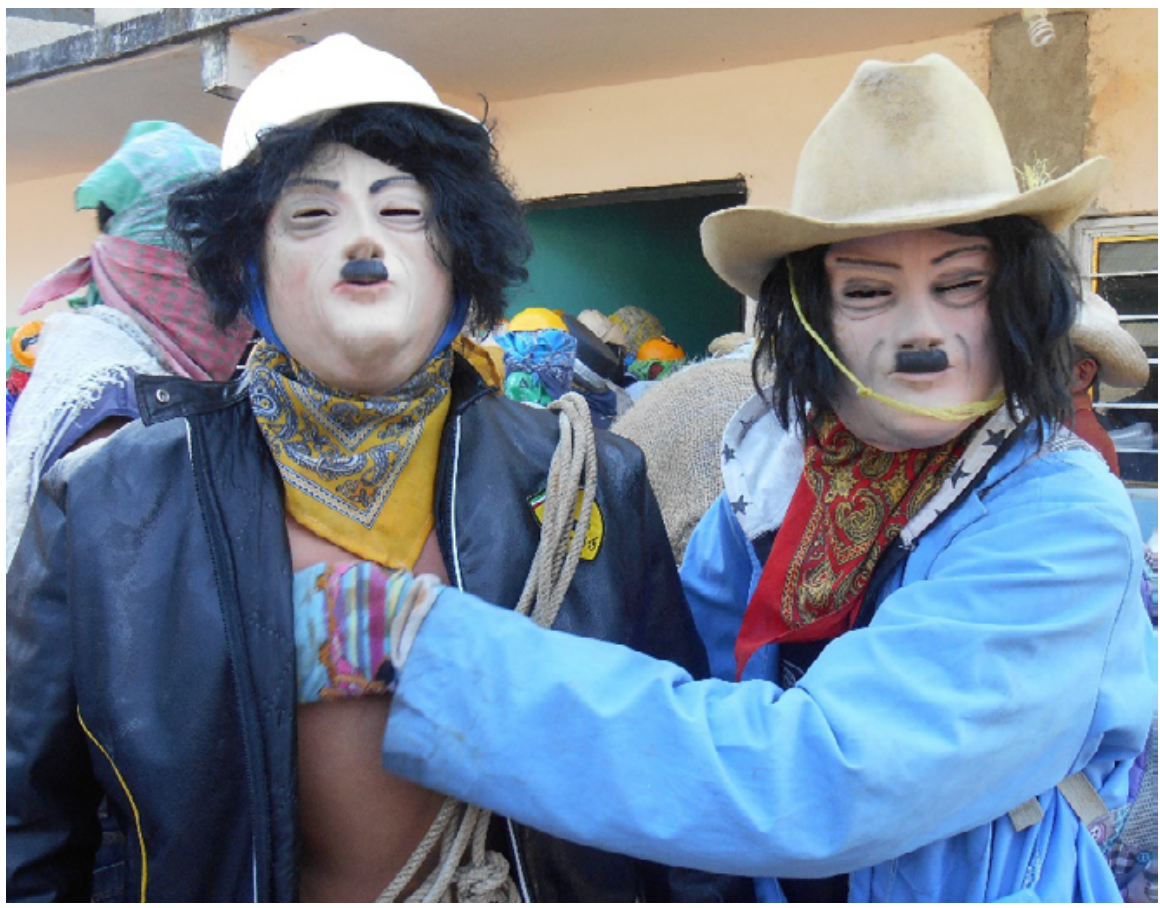

A este juego que es el Carnaval los otomíes le llaman ëni y le atribuyen una fuerte carga sexual, como ya lo mencionó Galinier (1990). Todo acto sexual que se representa en el Carnaval ya sea entre el hombre y la naturaleza, o entre el hombre y sus antepasados que habitan la naturaleza, genera un juego entre la durante el Carnaval. Reinoso, 2014. muerte y la vida, genera una pérdida de nzahki o fuerza corporal y cósmica, que se pierde por medio del intercambio y el agotamiento de fluidos. Los actores en esta fiesta realizan la representación de un acto sexual sagrado que tiene una doble relación, por un lado, el hombre con el cosmos y, por otro, el hombre con sus antepasados.

Durante la fiesta el cuerpo de los actores adquiere cualidades de un cuerpo dual femenino/masculino (si es un hombre disfrazado de mujer) y muerte/ vida (si es un hombre disfrazado de diablo o alguna otra antigua). En este sentido el Carnaval le permite al humano mediante un juego sagrado aprehender el mundo, pensarlo a través de una relación sexual y cósmica con la naturaleza, para generar una muerte y seguir viviendo en el mundo. 
Imagen 5. Juegos sexuales durante el Carnaval. Reinoso, 2014.

Un ejemplo que permite entender mejor las imágenes sexuales que se encuentran dentro del Carnaval otomí es la asociación que existe entre la imagen femenina y el diablo.

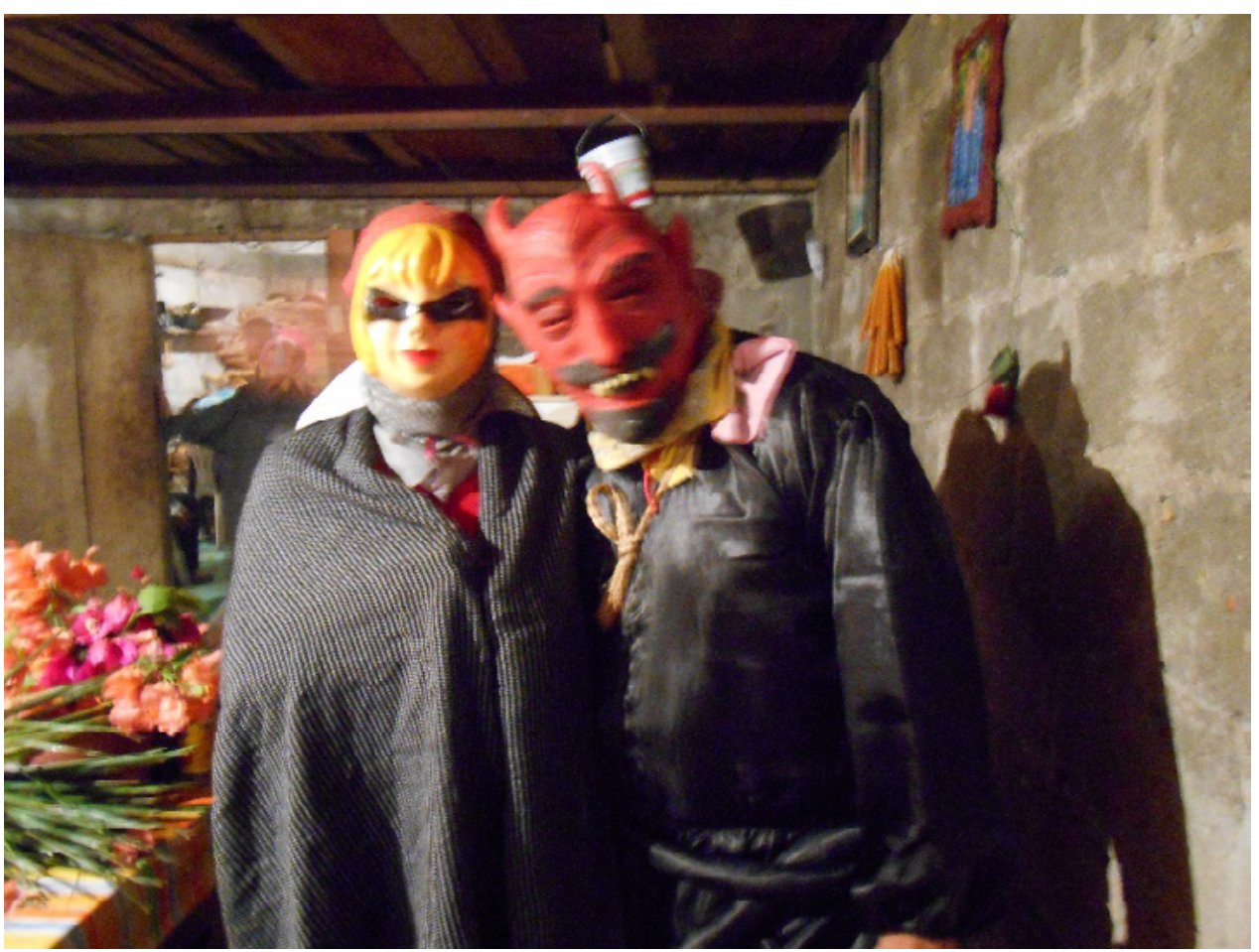

Menciona Galinier que el Carnaval es el momento del enfrentamiento entre los dos principios opuestos y complementarios, el masculino y el femenino, es la materialización de un gran juego sexual, donde el experto jugador es el diablo, el dueño del mundo, de la muerte, del sacrificio. Por esta razón "se trata de una fecundación de las mujeres, de la creación de nuevas generaciones" (Galinier, 2001: 473). En donde el diablo, o el dios chivo (debido a los cuernos que porta), va a llegar a fecundar a las mujeres; por medio del baile va a perder su fuerza vital hasta que se encuentre viejo y debilitado y muera. Con este ejemplo se ve claramente la relación que hay entre el diablo y la figura femenina, ambos pertenecientes a la mitad inferior del mundo.

Cabe destacar que: "Según las glosas carnavalescas, el sexo de la mujer es el lado "torcido" del mundo" (Galinier, 1990: 540). Por esta razón, todo el tiempo está poniendo en peligro y desequilibrando la armonía que existe entre la comunidad y el cosmos. El diablo, por ser el fecundador que viene a visitar a las mujeres, también representa el deseo, perteneciente al lugar del coito, de lo prohibido, donde las sustancias vitales se van a renovar y purificar para vivificar al mundo. Galinier al respecto menciona:

Los rituales de "apertura" tal como el Carnaval indígena, están destinados precisamente a liberar estas fuerzas psíquicas en el mundo, liberación de la que llevan huella el lenguaje, la movilidad, la subversión temporal de las relaciones de autoridad. Se trata de una "elevación" del "mundo de abajo" materializada por el 
1 Es una metáfora que utiliza el autor para referirse a una primera categoría, se podría decir a una categoría de primera edición. La clave de los sueños es para el autor, una categoría de primera edición.
Imagen 6. Bädi

ofrendando en el Carnaval. Reinoso, 2014. camino seguido por estos "viejos", los ancestros salidos del monte (...), que vienen durante algunos días a compartir la existencia de los vivos, a "derramar su sangre" (khi) es decir su esperma, antes de desaparecer de nuevo (Galinier, 2009: 133).

\section{El bädi y los sueños}

La obscuridad y el sueño representan para los otomíes la incertidumbre, lo desconocido, se produce una "muerte" durante el sueño, un estado no consciente que se experimenta al entrar la noche, donde los antepasados muertos se hacen presentes y, a su vez, los humanos pueden ir al lugar de las antiguas. Dicha visita es posible gracias a que durante el sueño se pierden algunas partes del cuerpo, por ejemplo, dahi (aire), mbui (corazón), tezä (denominado por Galinier la cosa sexual), entre otras. El estado onírico se vive como algo real y en él se gasta una gran parte de la energía vital del cuerpo humano, sin embargo, la energía se está renovando todo el tiempo gracias a acciones rituales como limpiar al cuerpo, consumir ciertos alimentos, etcétera. Al respecto Galinier manifiesta:

Para los otomíes, el cosmos es el lugar de una necesaria fragmentación. Las leyes del sueño no tienen su explicación en el simple campo de la biología humana. Ellas radican en una cosmología general que utiliza categorías a priori del espacio y del tiempo. Por eso los sueños revisten necesariamente un carácter estereotipado; están almacenados en la memoria colectiva y "brotan" de manera repentina a través de la experiencia de un sujeto dado, al cual no "pertenecen". El que exista una "clave de los sueños" da la medida de este saber colectivo, que utiliza experiencias individuales para hacerlas explícitas de inmediato. [...] La "clave de los sueños" es interna al mismo saber colectivo, como la expresión de una categoría prínceps', interna a la razón cultural otomí (2001: 478).

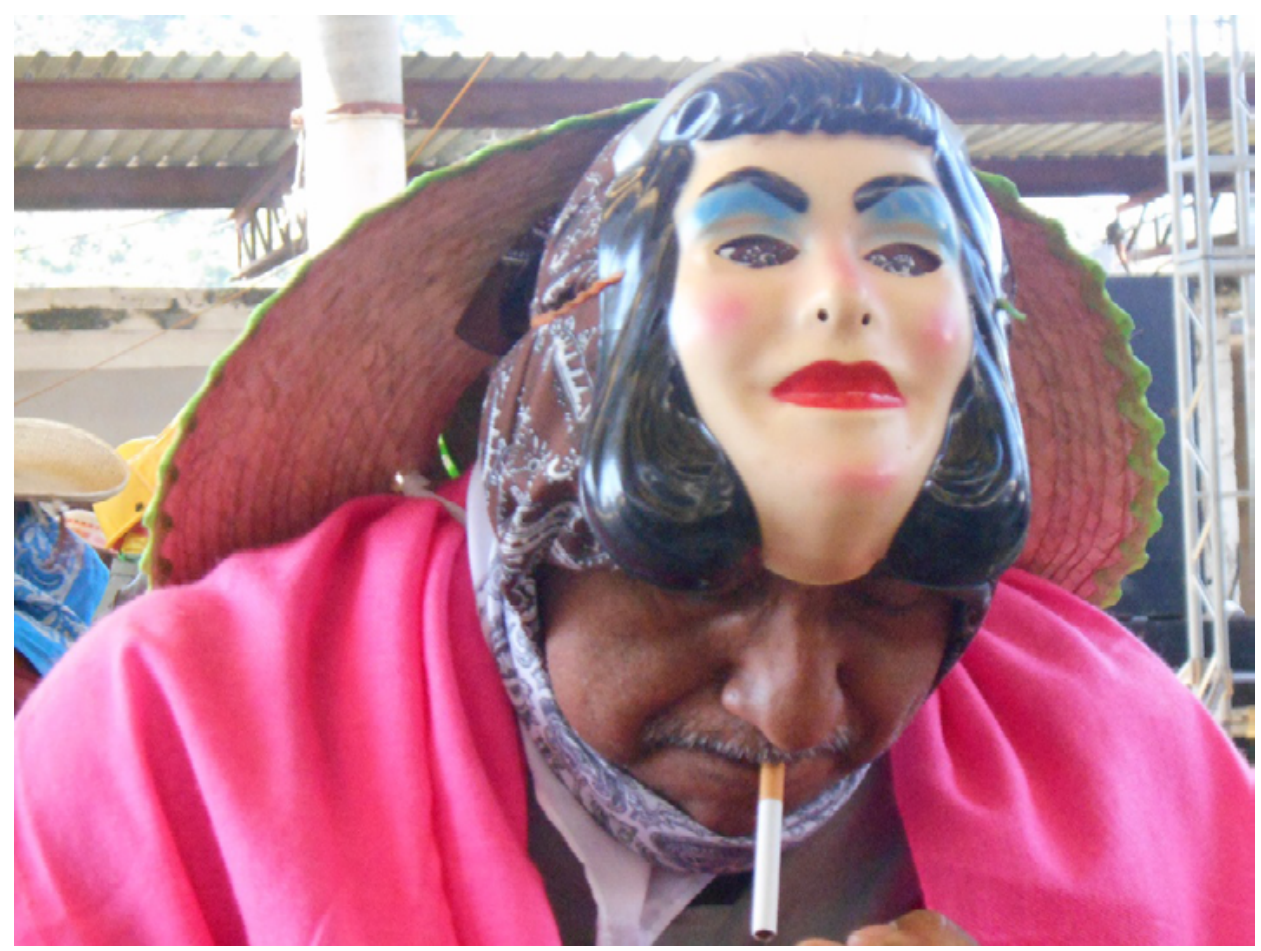


Imagen 7. Bädi limpiando a la gente durante el Carnaval otomí. Reinoso, 2017.
Esta información de los acontecimientos del otro mundo que ve la persona mientras duerme está cargada de un código, un mensaje de los antepasados muertos para los vivos que sólo el bädi, "el que sabe", va a poder descifrar. Es él quien puede interpretar lo que vive la persona en el sueño, quien conoce "la clave de los sueños". Es también a través de los sueños que el bädi recibe su don y aprende el trabajo sagrado, donde las antiguas, específicamente Zithu, el diablo, se manifiestan como maestros de los curanderos. Durante el sueño el bädi mantiene comunicación con "el patrón" para realizar su trabajo.

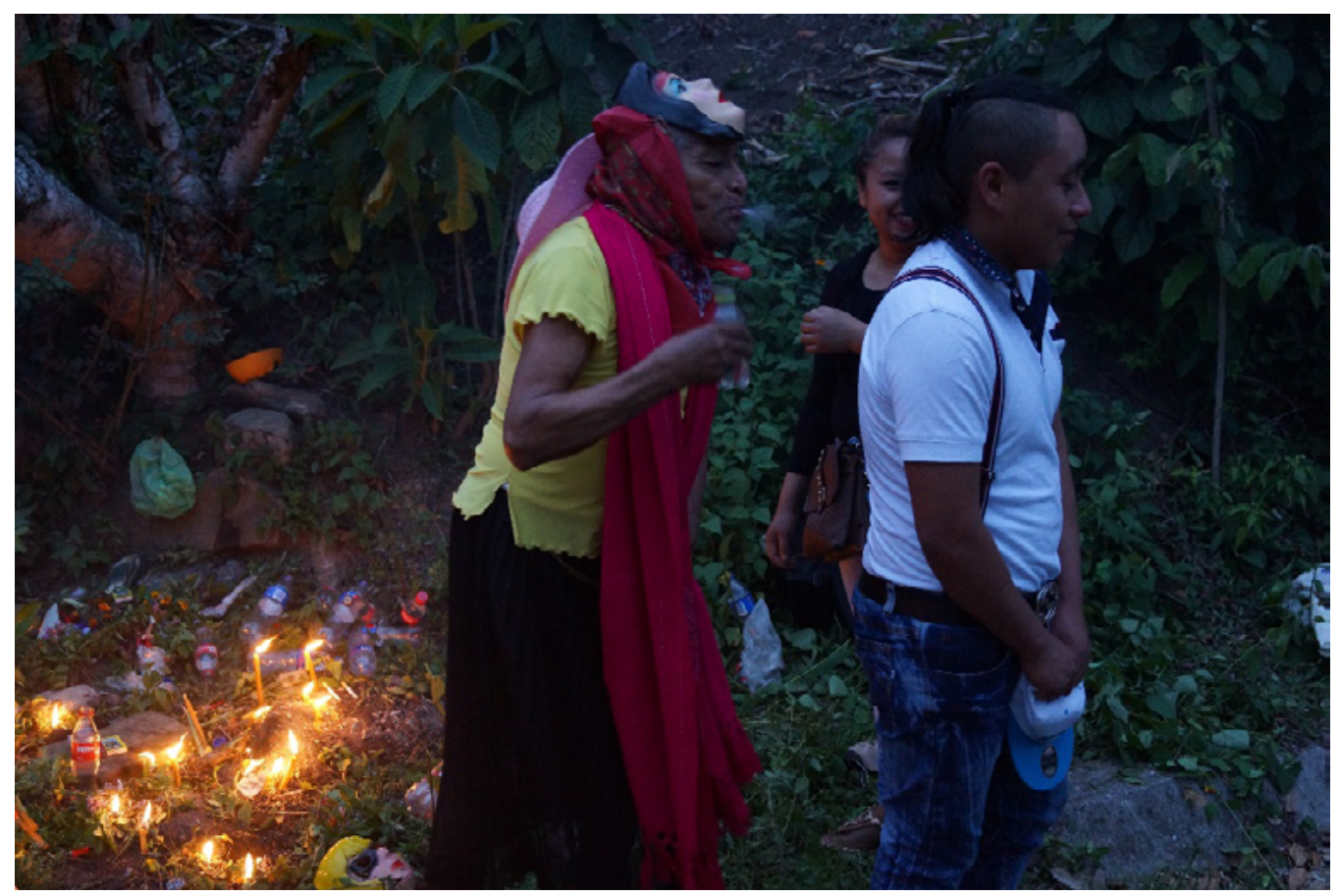

El sueño es parte de la estructura que conforma la realidad otomí y el gran conocedor del sueño es el especialista ritual. Lo que el bädi aprende y ve en el sueño, lo pone en práctica en los rituales, ya sea una limpia, un costumbre o Carnaval, los cuales tienen la función de propiciar el bienestar de la comunidad.

Según las narraciones de los bädi, cuando las antiguas se les aparecen en los sueños tienen una petición constante, siempre piden ofrenda, es decir, costumbre. Por eso, los rituales y el sueño tienen como función primordial establecer un diálogo entre la comunidad y sus deidades. Durante un ritual, el especialista entrará en trance, para prestarles su cuerpo a las antiguas y que ellas hablen a través de él. De hecho, el discurso que manifiestan las deidades durante el sueño es el mismo que manifiestan durante el trance los bädi. Por esta razón, dentro de la cultura otomí, no se pueden separar las vivencias oníricas y los curanderos, el ritual y el trance, ya que forman parte de un mismo diálogo. 


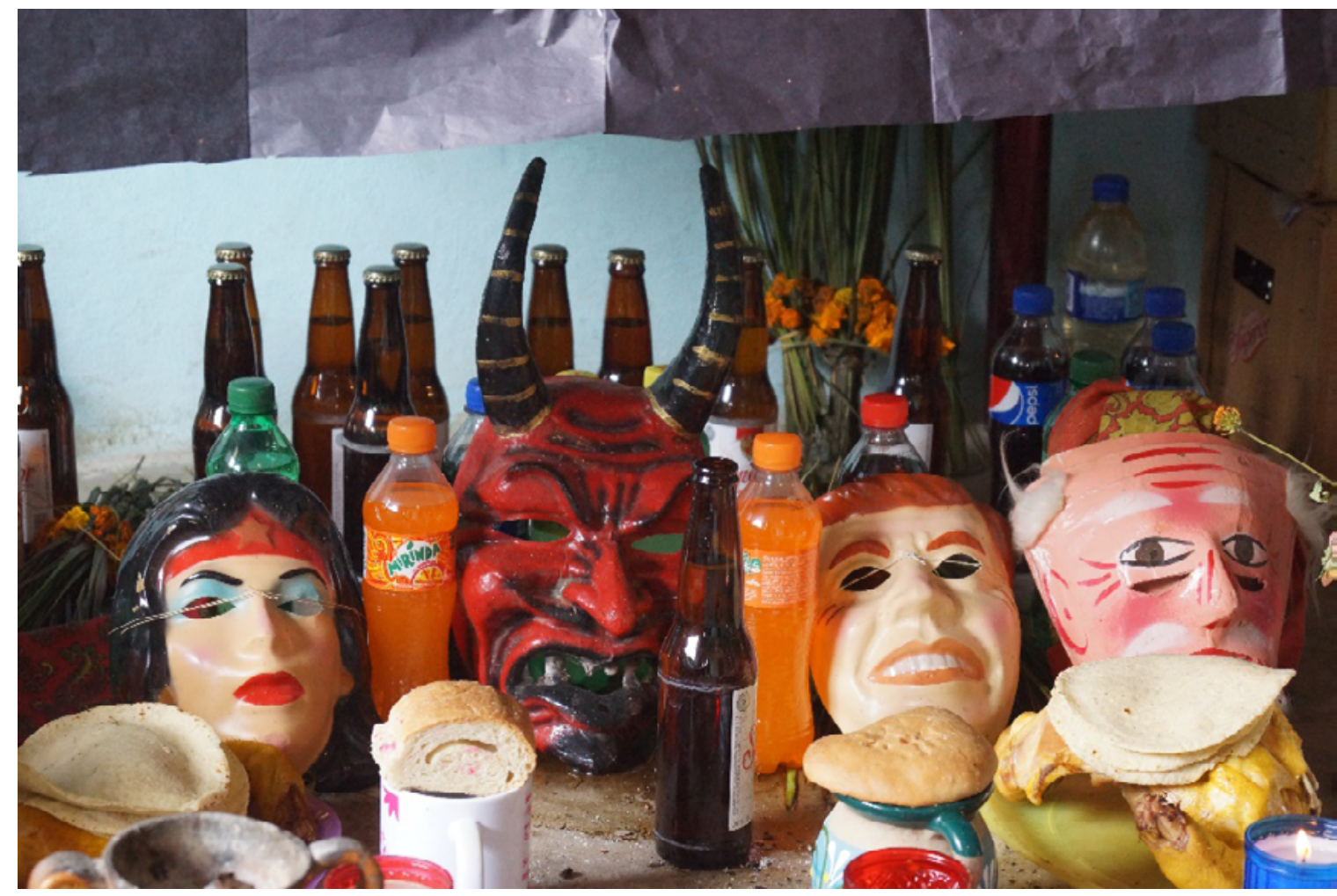

Imagen 8. Ofrenda de Carnaval otomí. Reinoso, 2017.

\section{El bädi en el Carnaval otomí de Ixtololoya}

El contexto más importante en el que se encuentran los humanos y Zithu el diablo es en el Carnaval otomí. En Ixtololoya el Carnaval es la fiesta para Zithu, la comida, la bebida, el baile, la música y las máscaras son de y para él, sobre el Carnaval en Ixtololoya nos dice Mario Castro:

Se hace aquí el Carnaval, para ofrendar al diablo por dar trabajo, por las cosechas, por darnos la vida y todo lo que nos da. Se comienza a hacer el Carnaval en las fechas cuando empieza la cuaresma porque antes, aquí el diablo andaba buscando a dios. Dios se entera de esto y decide programar la fiesta de Carnaval para ponerse la máscara y que el diablo no lo reconozca. El diablo estaba muy enojado buscando a dios para matarlo. Para que no lo encuentre dios hace esta fiesta en donde todos van enmascarados y se pone la máscara, como los que bailan. El diablo llega a la fiesta y no puede saber cuál de los enmascarados es dios.

Dios manda a sus ayudantes a darle mucha comida y bebida al diablo para entretenerlo y se olvide que estaba enojado buscando a dios. Por eso todas las ofrendas del Carnaval son para el diablo, para que no busque a dios. Por eso el diablo se adueña de todo en la fiesta del Carnaval y ya se quedó la tradición así, de darle ofrenda al diablo, porque la gente se dio cuenta que quien le ofrenda al diablo, le va bien en su cosecha, en su trabajo y hasta hoy le seguimos ofrendando porque nos va bien si lo hacemos (Mario Castro, Ixtololoya, 21/02/2017). 
Imagen 9. Bädi con ofrenda de Carnaval otomí. Reinoso, 2017.

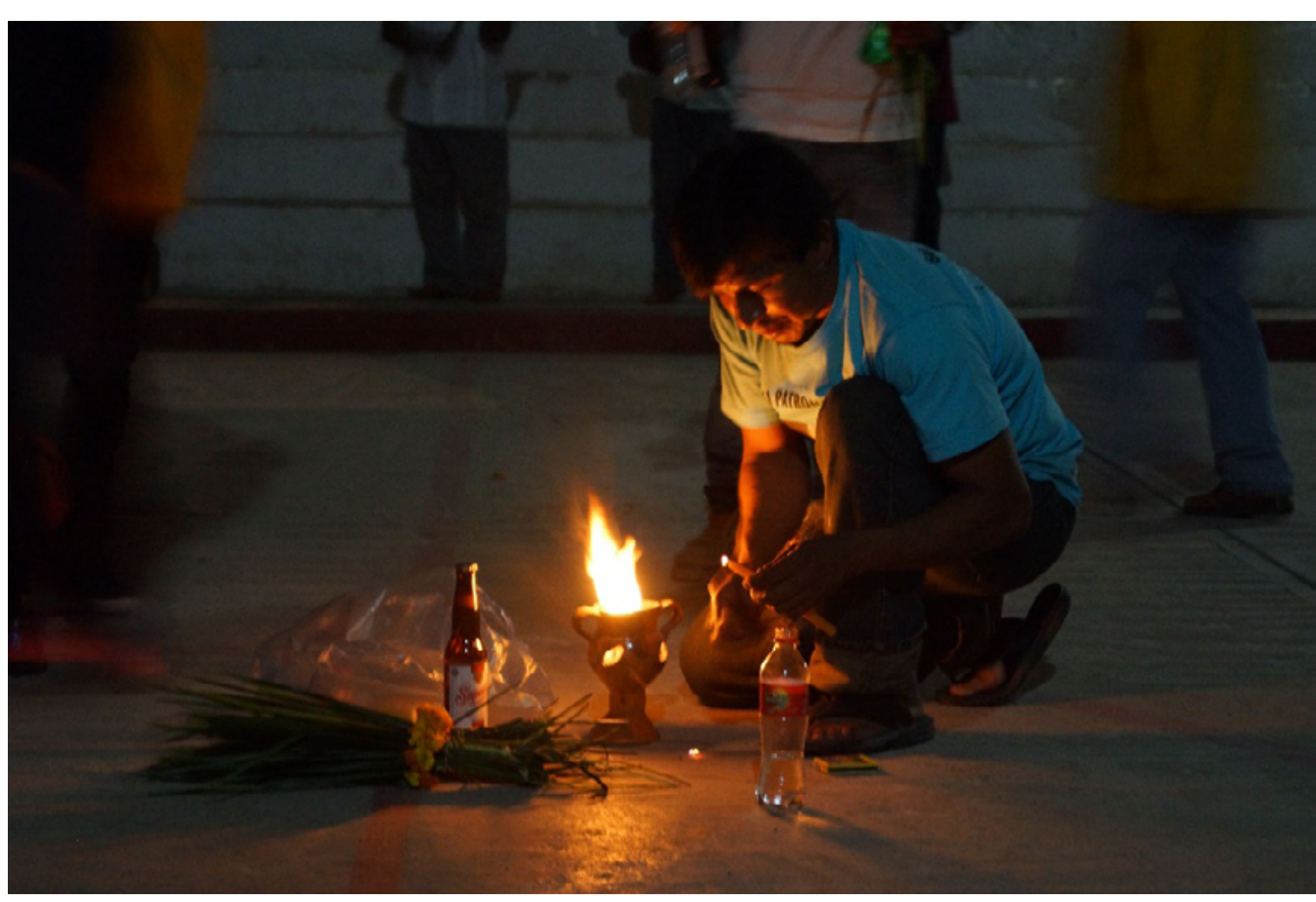

Después de ver varios carnavales consecutivos en Ixtololoya, pude reparar en la importancia de la labor del curandero durante esta fiesta. Unos días antes de que comience la festividad, Zithu se les presenta a varios curanderos del pueblo en los sueños, para pedirles ofrenda. Les manifiesta qué es lo que quiere comer y beber en su fiesta. De esta forma, se comienzan a poner los altares en la casa de los curanderos que lo sueñan. No obstante, también son colocados en las casas de los mayordomos.

En 2017 en Ixtololoya el Carnaval otomí se llevó a cabo del 1 al 4 de marzo. Unos días antes, el 26 de febrero, el bädi Leopoldo realizó en su casa un pequeño costumbre en honor a Zithu, ya que se le presentó en el sueño y le dijo que él debía hacer una limpia para todos en el pueblo antes de que empezara el Carnaval porque las personas: "Quieren fiesta, pero en la fiesta hay peleas, hay muertos, por eso hay que hacerle una limpia a todo el pueblo. Por eso los curanderos tienen que trabajar en Carnaval" (Leopoldo, Ixtololoya, 21/02/2017). 
Imagen 10. Ofrenda de Carnaval otomí. Reinoso, 2014.

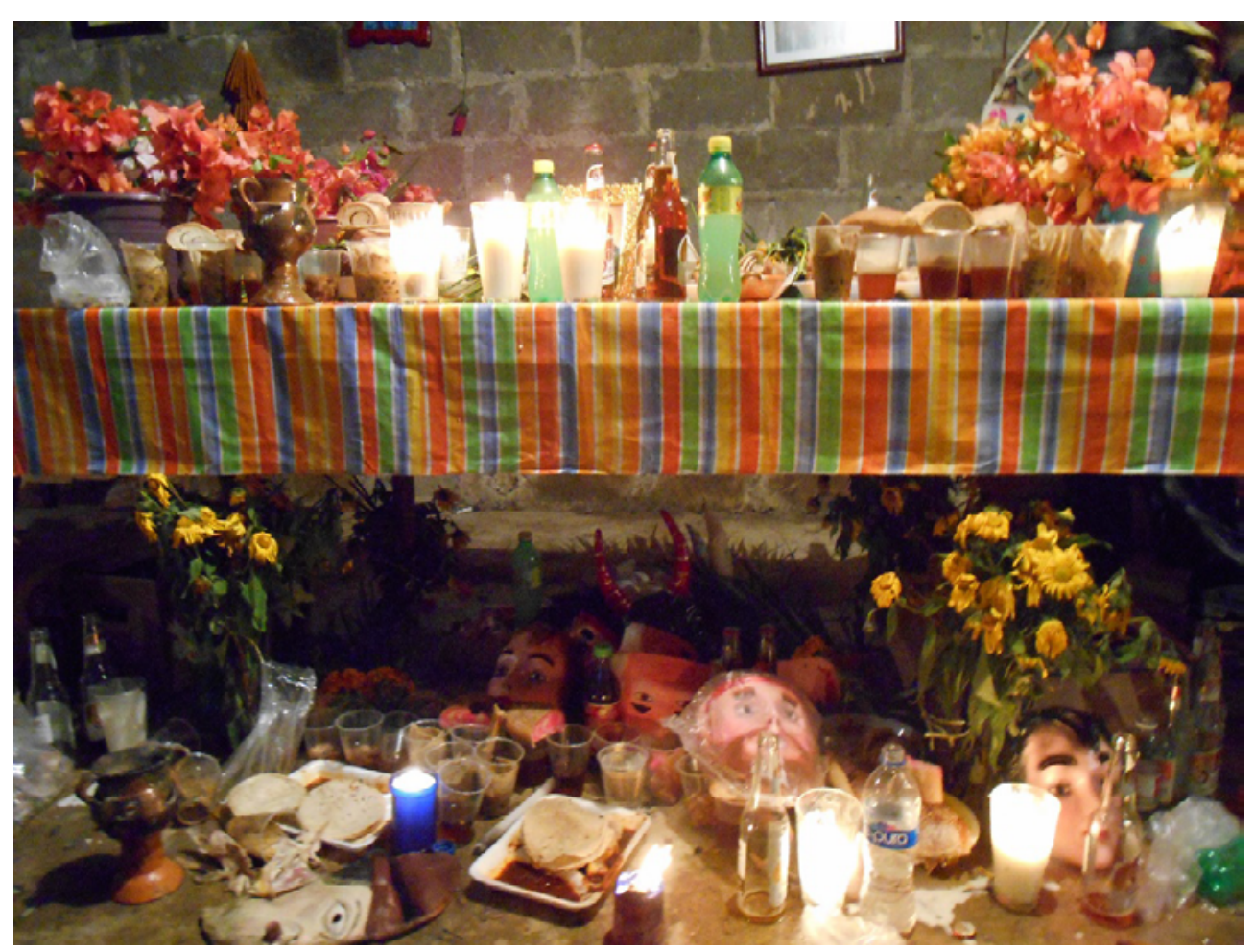

El bädi Leopoldo escuchó las peticiones de Zithu y cuenta que tardó dos días en preparar todo lo que utilizó para esta limpia. Ese día, en primer lugar, el bädi Leopoldo y la bädi María realizaron un pequeño costumbre en la casa del primero enfrente al altar de Zithu. Después Leopoldo prendió velas en la cancha en honor a su maestro, como lo hacen todos los curanderos que participan del Carnaval. Y finalmente dejó ofrenda en la iglesia.

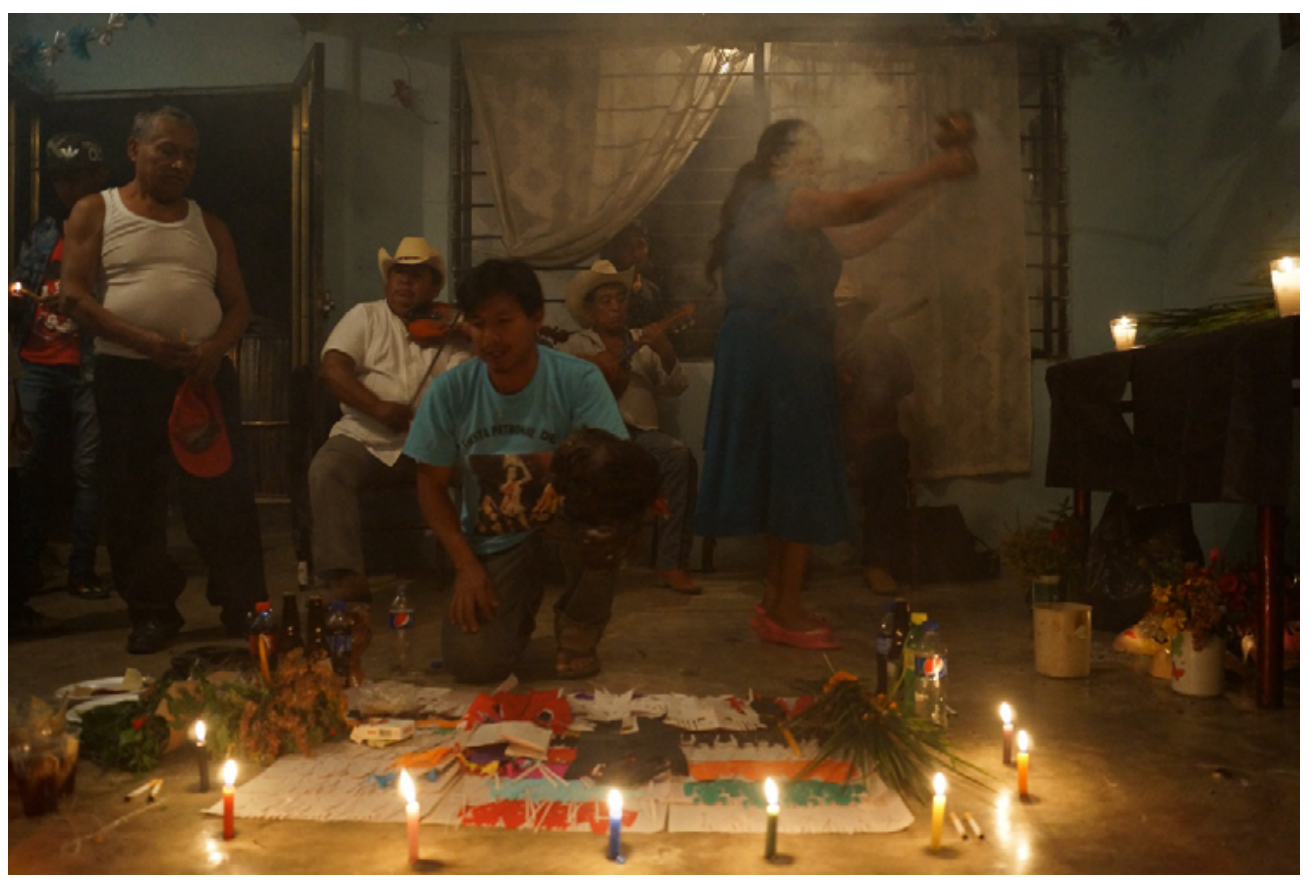

Imagen 11. Ofrenda de bädi para Zithu. Reinoso, 2017. 
El papel del bädi es trascendental en el Carnaval, ya que cada curandero que sueña al patrón, le pone en su casa una ofrenda a Zithu, y cada día se visita la casa de un bädi y se baila alrededor de la ofrenda. El curandero invita a los asistentes comida y cerveza. Cuenta Mario, bädi de Ixtololoya, que:

Los curanderos están obligados a poner ofrenda y participar en Carnaval porque Zithu te ayuda todo el año a trabajar, te enseña a hacer tu trabajo y por eso tienes gente que te busca para curarse, por eso cuando es su fiesta, hay que darle algo, no es obligación darle mucho, pero sí, lo poquito que puedas, pues él es el patrón, el Presidente de la tierra, el dueño del mundo, el dueño de todo (Mario Castro, Ixtololoya, 21/02/2017).

Imagen 12. Bädi enfrente de una ofenda de Carnaval. Reinoso, 2017.

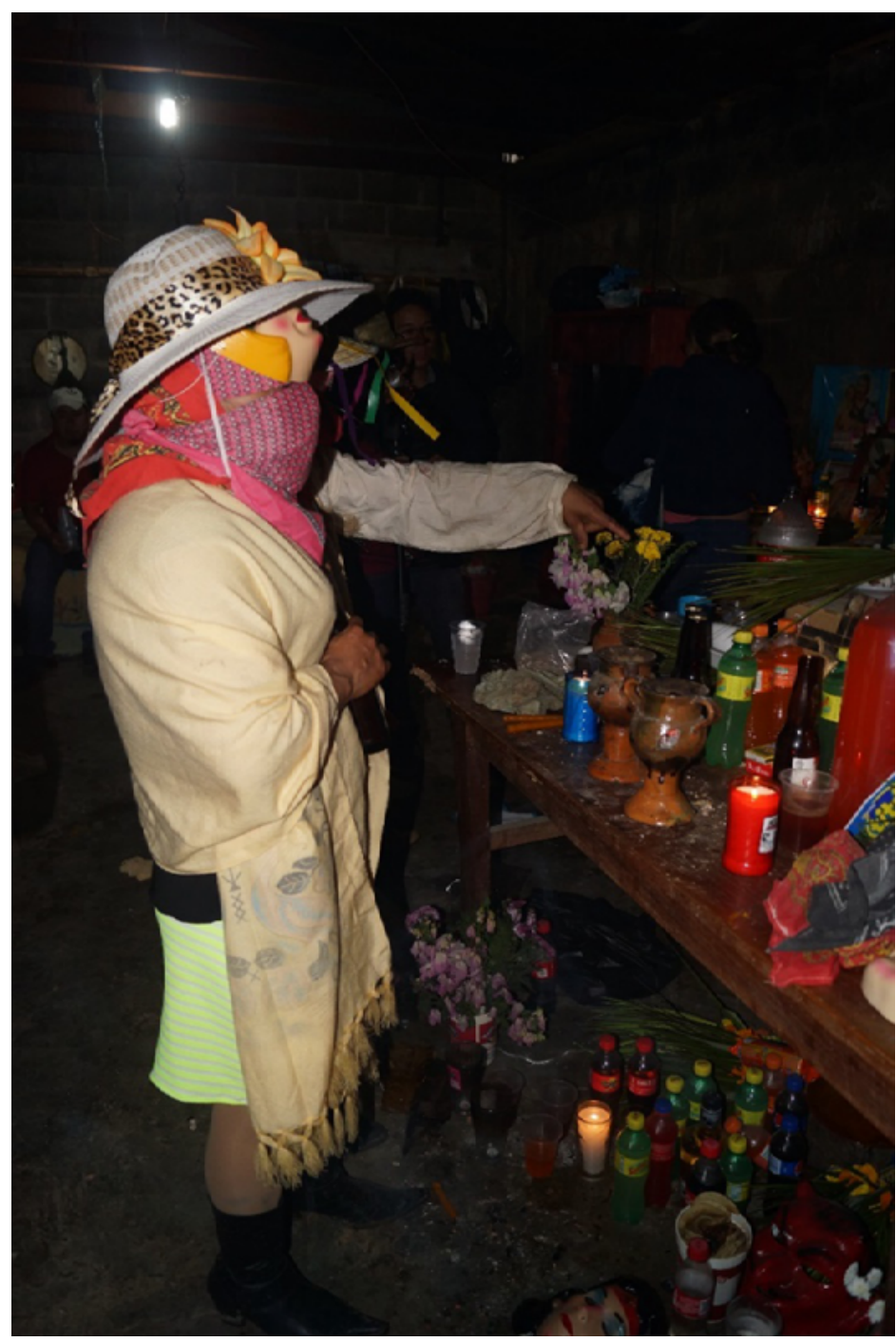




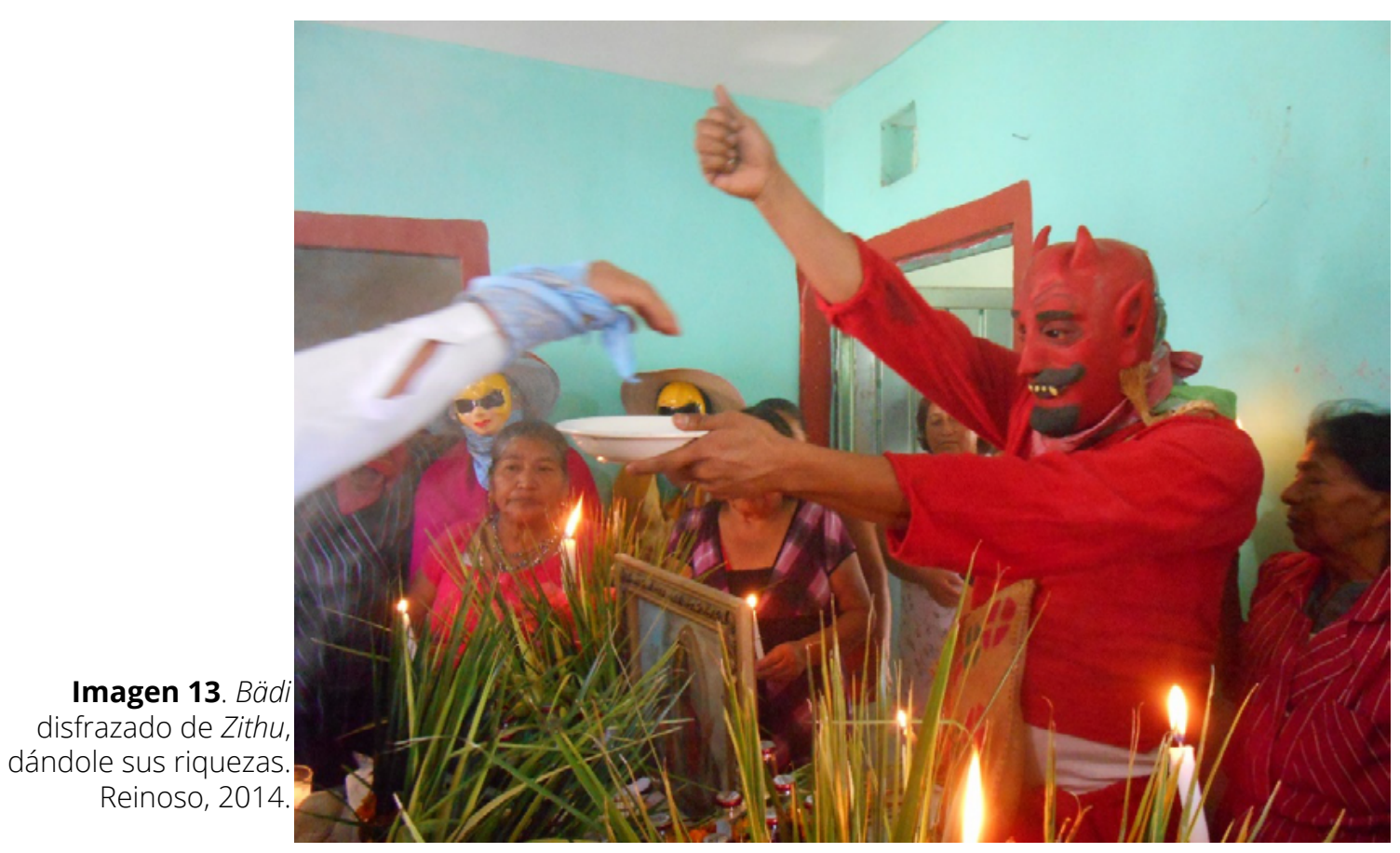

Hay muchos curanderos que ponen ofrenda en honor a su maestro, pero también que hacen "el compromiso de bailar", que se vuelven bailadores del Carnaval:

Si prometes bailar, tienes que hacerlo por siete años, durante este tiempo tienes que seguir la tradición bailando en Carnaval. En el camino te vas dando cuenta cómo te bendice el baile. Zithu te bendice en todos los aspectos hagas lo que hagas, por ejemplo, si quieres empezar un negocio y no tienes dinero, puedes dar de comer en Carnaval a los que bailan. Pones un plato y una vela y las personas te dejan dinero ahí en el plato, se avisa a la gente que tal señor va a dar de comer y las personas te apoyan, van a tu casa y te ayudan con dinero y con esto das de comer, así se le hace si tú no tienes dinero. Todo el dinero lo ocupas para darles de comer a los bailadores de Carnaval y el dinero que te sobra lo ocupas para empezar a trabajar, por eso dicen que el diablo te ayuda a empezar a trabajar. Porque el mismo diablo anima a la gente a que vayan y te ayuden con dinero. Las personas que dan de comer a los bailadores deben dar de comer por cuatro años, y ahí se empieza a levantar la persona (Mario Castro, Ixtololoya, 21/02/2017).

Otra de las actividades fundamentales que realiza el bädi durante el último día de Carnaval en Ixtololoya es la última limpia, que es realmente grande y requiere del trabajo de varios curanderos. En primer lugar, dos o tres de ellos, disfrazados generalmente de Zithu, limpian a todos los miembros de la comunidad en las puertas de la iglesia. 
Imagen 14. Bädi realizando su trabajo durante el Carnaval. Reinoso, 2017.
Imagen 15. Disfraz del diablo ofrendado al final del Carnaval en la milpa. Reinoso, 2017

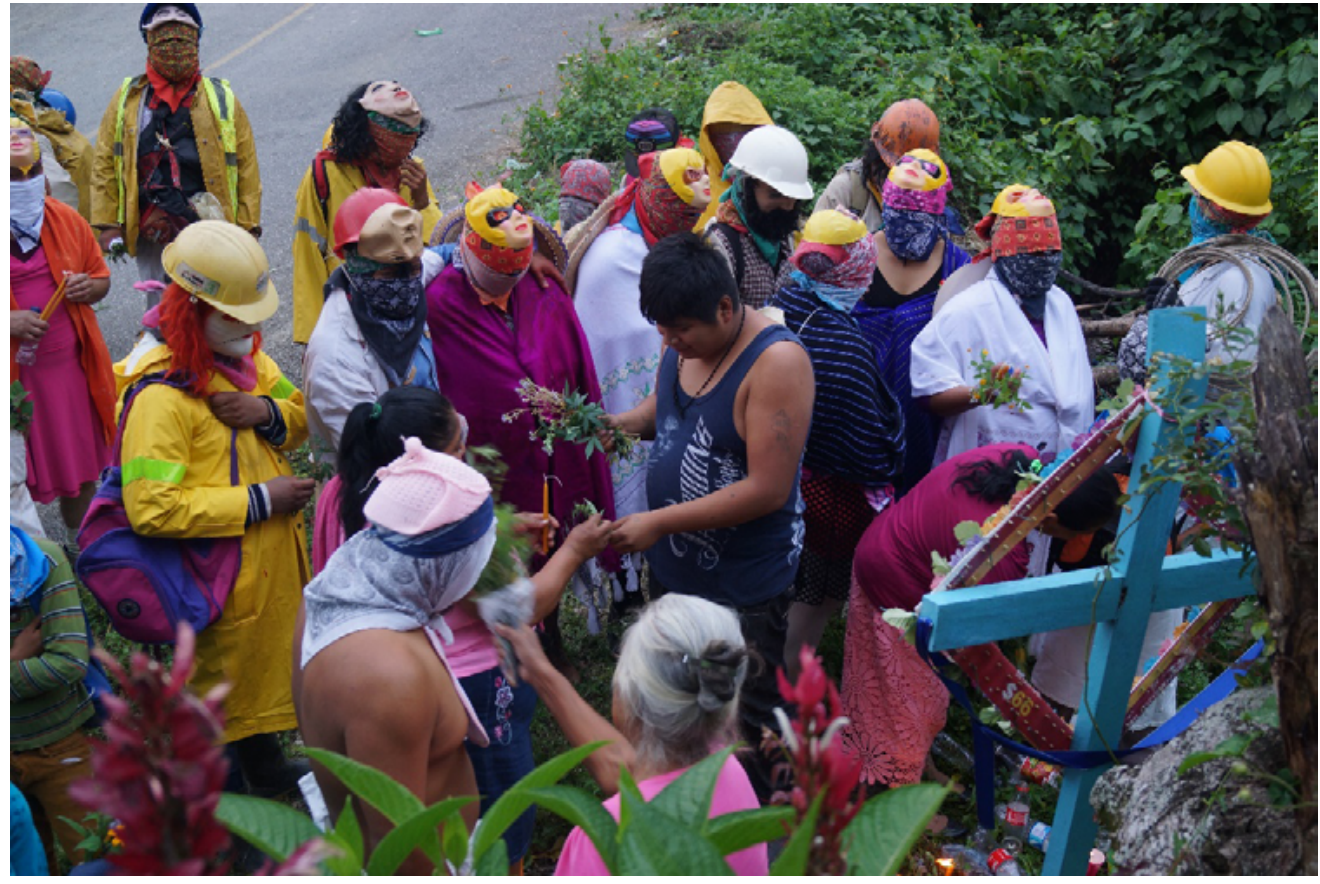

Posteriormente, los habitantes de la comunidad se dirigen hacia una de las cruces que está en la entrada o salida del pueblo, en donde todos los asistentes al Carnaval son limpiados por última vez por otros curanderos. Después, los curanderos se limpian entre ellos. Al último, se van al monte o a la milpa, a donde nadie los vea, a quitarse el disfraz y agradecerle a Zithu los favores brindados y el trabajo enseñado. Allí le ponen una pequeña ofrenda personal y con esto queda terminada su labor en el Carnaval hasta el próximo año.

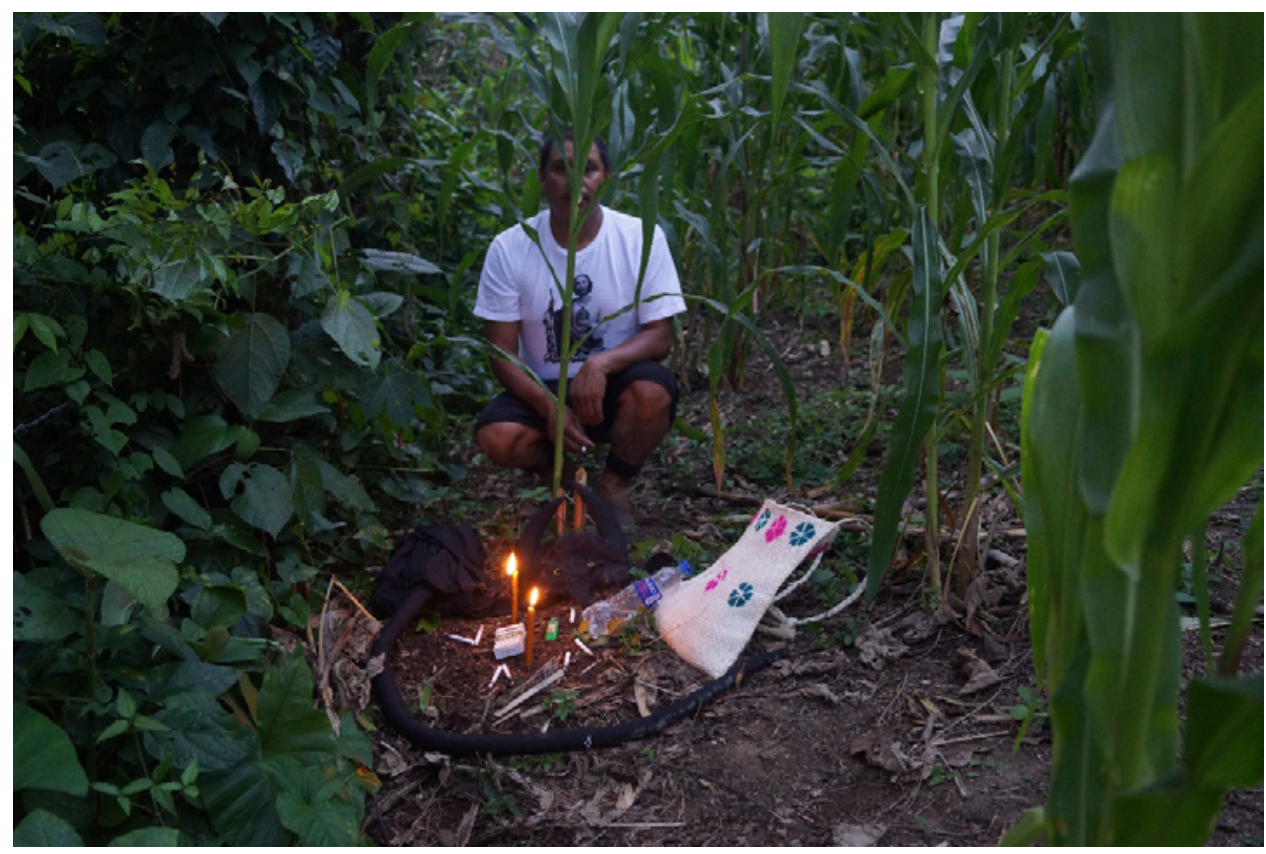




\section{Conclusiones}

En los últimos años, debido a que la fiesta de los Tres viernes se superpone con la del Carnaval, las autoridades de la iglesia católica del municipio de Pantepec han pedido a las comunidades que no celebren la fiesta, petición que es rechazada debido al carácter sagrado y a la importancia que tiene para los otomíes.

Mientras el Carnaval transcurre, a través del juego del acto sexual se establece una relación sexual-ritual con el cosmos y las antiguas. El Carnaval otomí es un tiempo de inversión y de descontrol, en donde los muertos llegan a jugar con los vivos.

El sueño para los otomíes es un acontecimiento real que antecede al ritual. Observando el Carnaval podemos ver cómo el mundo del sueño y del ritual se unen en un diálogo continuo. Las ofrendas de Carnaval son la materialización de los deseos de Zithu.

\section{Referencias}

- Dow, James (1974). Santosy supervivencias. Funciones de la religión en una comunidad otomí, México. México: INI-SEP.

- Galinier, Jacques (1990). La mitad del mundo. Cuerpo y cosmos en los rituales otomíes. México: UNAM-INI.

* Galinier, Jacques (2001). Una mirada detrás del telón. Rituales y cosmovisión entre los otomíes orientales. En Johanna Broda y Jorge Félix Báez (coords.), Cosmovisión, ritual e identidad de los pueblos indígenas de México (pp. 453-484). México: FCE.

* Galinier, Jacques (2009). El espejo otomí. De la etnografía a la antropología psicoanalítica. México: CEMCA-INAH-Comisión Nacional para el Desarrollo de los Pueblos Indígenas.

* Robledo Leal, María Isabel. (2005). Cosmovisión lunar Otomí y su trascendencia en el Carnaval Xhita, comunidad de "Las Huertas", Municipio de Jilotepec, Estado de México. México: ENAH-INAH.

* Siqueiros García, Jesús Mario. (1997). Aproximación etnográfica del Carnaval Otomí de San Pablito, Puebla. Cuerpo, sociedad y cosmos. México: ENAH-INAH.

* Williams García, Roberto (1963). Los Tepehuas. México: Universidad Veracruzana.

\section{Cómo citar este artículo}

* Reinoso Niche, Jorgelina (2019). Sueños del Carnaval otomí en la Sierra Norte de Puebla. Revista Digital Universitaria (RDU). Vol. 20, núm. 2 marzo-abril. Dol: http:// doi.org/10.22201/codeic.16076079e.2019.v20n2.a4. 